\title{
Learning to be a psychostimulants addict with self-regulation therapy
}

\author{
Salvado Amigó. \\ Departament de Personalitat, Avaluació i \\ Tractaments Psicològics \\ Universitat de València \\ Valencia, Spain \\ Salvador.amigo@uv.es
}

\author{
Joan C. Micó. \\ Intitut Universitari de Matemàtica \\ Multidisciplinar \\ Universitat Politècnica de València \\ Valencia, Spain \\ jmico@mat.upv.es
}

\author{
Antonio Caselles. \\ IASCYS member \\ Departament de Matemàtica Aplicada. \\ Universitat de València \\ Valencia, Spain \\ Antonio.Caselles@uv.es
}

\begin{abstract}
This article presents the results of a single-case experiment of alternative treatments in which a participant applied the Self-Regulation Therapy (SRT) to reproduce the effects of a stimulant drug, methylphenidate, and a sedative, alcohol. The SRT is a learning procedure based on classic conditioning and suggestion that reproduces the effect of drugs by remembering the effects they have. The participant reproduced the effects of both drugs during ten sessions held on 5 consecutive days. To record effects, adjective scales were used that measured Drug effect, High, Rush, Energy, Tension and the General Factor of Personality (GFP). The results indicated that the participant was capable of independently reproducing the effects of both the above-cited drugs, and that most of these effects were graphically represented as an inverted $U$-shape. This inverted $U$ can be interpreted as a process in which effects of drugs become progressively more marked (sensitization) to become progressively less marked (tolerance). In this way, the inverted $U$ represents the equivalent to a complete process of becoming addicted to a drug. The participant "learnt to be an addict" without using drugs. The theoretical implications and therapeutic potential of this procedure are discussed.
\end{abstract}

Keywords- Addiction; Self-Regulation Therapy; sensitization drug; tolerance drug; General Factor of Personality; methylphenidate; alcohol.

\section{Introduction}

Different addiction models can explain the process by which drug use becomes abuse and compulsive drug use $[1,2]$. Among the most outstanding addiction models we find those based on the opponent process theory of addiction [3,4,5], the incentive-sensitization of addiction $[6,7]$, and neurobiological addiction models $[8,9]$.

Despite their differences, these models share some characteristics, like the importance attached to nonassociative processes such as pharmacological sensitization and tolerance, and learning processes (classic and operant conditioning) when explaining the origin and development of addiction, and also of relapses.

Learning models of addiction underline the importance of environmental stimuli in addiction developing. Drugs classic conditioning has been amply demonstrated in experiments done with animals and humans by conditioning positive effects, as well as sensitization, tolerance and drug withdrawal [10,11,12].

In studies into learning addictive behavior through classic conditioning, emphasis has been placed on the CS-US (Conditioned Stimulus - Unconditioned 
Stimulus) association to explain the learning of positive drug effects. However, very little attention has been paid to the nature of the Conditioned Response $(C R)$ and its relevance in the addiction process or therapeutic intervention. Therefore in those treatments administered to lessen the conduct learnt by classic conditioning, the extinction procedure is designed to handle the CS-US association while waiting for the $C R$ to be easily eliminated [13].

One learning process has been designed specially to reinforce the $C S-C R$ association. This procedure is known as the Self-Regulation Therapy (SRT) [14,15], which is based on applying classic conditioning and suggestion from the cognitive-behavioral perspective of hypnosis [16]. The main objective of its design was to help reproduce the positive effects of drugs; that is, to reinforce the $\mathrm{CR}$.

A detailed description of the SRT procedure is found in [15], along with a broad and complete experimental basis of the procedure. A summary of some studies and procedures is found in [17].

Most studies conducted with the SRT have demonstrated that it is possible to reproduce drug effects during a single session, but a few studies have been conducted with more sessions [18,19], and it was impossible to know if reproducing drug effects with time and during different sessions can produce a similar effects curve to that of addition; in other words, a progressively increasing intensity of the effect (sensitization), followed by a progressive drop in effects (tolerance, drug withdrawal). If this intensity curve of drug effects took place, it would be inverted U-shaped. Figure 1 is a simple schematic representation of an inverted U-shaped addictive process with the first stage of sensitization and a second tolerance/withdrawal phase.

Figure 1. Schematic representation of the drug addictive process with a first sensitization phase and a second tolerance/abstinence phase.

\section{ADDICTIVE PROCESS}

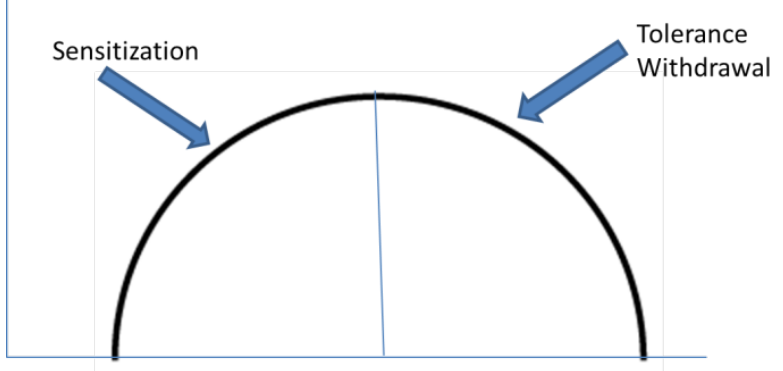

This article presents the results of a first experiment that intends to shed some light on this matter. It is a single-case experimental design of alternative treatments in which the subject, by applying the SRT, reproduced the effects of a psychostimulant, methylphenidate, and alcohol on 5 consecutive days.

The classic conditioning of the effects of psychostimulants, like cocaine, has been well demonstrated [20-22], as it has the classic conditioning of alcohol effects [23-28]. The SRT has proven efficient to reproduce stimulant effects of certain drugs like cocaine, speed and methylphenidate [29-34], although it has still not been used to date to reproduce the effect of alcohol.

If during different $S R T$ sessions some indication of sensitization and tolerance is noted, we can state that we are about to demonstrate the possibility of creating a "drugless" addictive drug process which, as discussed later, may have important consequences for research and treating addictions and other psychological disorders.

\section{Methodology}

Participant

The participant was a 50-year-old male, and an old patient of the author of this article. He voluntarily accepted to form part of the study and signed the informed consent.

\section{Instruments}

1. The Five-Adjective Scale of the General Factor of Personality (GFP-FAS) [35]. The five adjectives are: adventurous, daring, enthusiastic, merry and bored. The GFP-FAS is related positively with Extraversion, Agreeableness and Openness, and negatively with Neuroticism and Conscientiousness. However, it can integrate all basic traits of personality [35]. Two versions of the GFP-FAS were used: trait-format version and state-format version ("Are you like this at this moment?” or “do you feel so at this moment?”). The participant filled out the state-format version form every 15 minutes to obtain a situational measure of the GFP. Each adjective is self-rated on a 10-point continuum.

2. Effects of drugs. It comprises two adjectives, High and Rush, and an expression: Drug Effect. The scale scores go from 0 (no effect) to 10 (maximum effect). These adjectives have been used in a large number of studies on subjective drug effects, quite often in the Visual Analogue Scales (VAS) format. 
3. A short form of the Activation-Deactivation Adjective Check List ( $A D A C L)$ [36]. This is a multidimensional test of various transitory arousal states. There are five adjectives on each subscale, and each adjective is self-rated on a 10point continuum. Two subscales were chosen for this experiment: Energy and Tension. The adjectives included in these two subscales were: energetic, lively, active, vigorous, and full of pep, and tense, clutched-up, fearful, jittery, and intense.

\section{Experimental design and procedure}

This is a single-case experimental design of alternative treatments. The patient usually consumes alcohol, sometimes in large quantities, and even remembers the psychostimulant effects of methylphenidate, which he took for the last time 6 months earlier. He was taught to apply the $S R T$, a procedure which he was already familiar with, to specifically reproduce the effects of methylphenidate and alcohol. The participant had to reproduce the effects of both drugs alternatively and randomly on 5 consecutive days. During each session, he had to complete adjective scales (Drug Effects, High, Rush, Energy, Tension, GFP-FAS) on a Likert scale from 0 to 10 points. We call each occasion on which the participant had to reproduce the stimulant effect the "Stimulant Condition", and each occasion on which he had to reproduce the alcohol effect the "Alcohol Condition”.

For both experimental conditions, the participant had to complete all the scales before applying the SRT so that the Baseline was recorded. After applying the $S R T$ to reproduce stimulant effects, he had to complete the scales again while experiencing the maximum euphoric effect, and yet another time when the euphoric effect had substantially reduced and the participant felt relaxed. So we can distinguish three Stimulant Condition phases:

1. Baseline

2. Maximum euphoric effect experienced

3. Relaxing effect experienced

We distinguished two phases for the Alcohol Condition:

1. Baseline

2. Maximum effect experienced that is similar to alcohol

With this design it is possible to compare the reproduced effects of both the stimulant and alcohol in relation to the baseline, and with each other. With the three Stimulant Condition phases, the intention was to compare the two effect types that the stimulant produced until this effect had completely disappeared: euphoria followed by serenity, which we describe herein as "relaxation".

Next the results obtained in the experiment are presented as both statistical and graphical results. The statistics used was non-parametric as the sample (number of sessions) was small (five sessions for each drug). So, $\mathrm{N}$ was considered the number of sessions when adapting inferential statistics to the single-case experimental designs [37].

The graphical results offer the unique chance to visually observe how the points on the different scales evolve on 5 consecutive days. This is a good way of checking whether sensitization and tolerance processes occurred as this would indicate the possible development of drug addiction by the SRT; that is, "drugless".

\section{Results}

Table 1 offers the means and standard deviations of the scores on the different scales used in this study.

(The section Appendix, placed after the section References, is devoted to present figures and tables).

Friedman's test was used to compare the reproduction of the stimulant effects of methylphenidate in the three phases. The variables "drug effects", "high" and "rush" were not compared as they scored 0 at the baseline. To make the table simpler, 0 was not included, but a dash ( - ) was used instead.

Table 2 presents the result of the Friedman's test.

Table 2. Results of Friedman's chi-squared test for the Stimulant Condition. (Df.= degrees of freedom; Sig.= asymptotic significance).

\begin{tabular}{|l|c|c|c|}
\hline & Chi-squared & Df. & Sig. \\
\hline Energy & 8,316 & 2 & .016 \\
\hline Tension & 7,600 & 2 & .022 \\
\hline GFP-FAS & 8,400 & 2 & .015 \\
\hline
\end{tabular}

We can see how for Energy, Tension and GFGFAS, Friedman's test gave significant results; that is, significant differences appeared among the three scales for the different experiment phases: baseline, reproducing euphoric effects and reproducing relaxing effects.

For the pair-wise comparisons, the Wilcoxon test was used for the Energy, Tension and GFP-FAS scales of the ranges with signs for the related samples. The results are found in Table 3.

For the Stimulant Condition, reproducing the 
euphoric effects significantly increased Energy and GFPFAS compared to the baseline and the relaxing effects. The relaxing effect of the stimulant reduced Tension compared to the baseline and the euphoric effect $(\mathrm{Z}=-2.04$ and $\mathrm{Z}=-2.02$, respectively, with $\mathrm{p}<.05$ ). Reproducing alcohol with $S R T$ significantly reduced the score for Energy ( $\mathrm{Z}=.-2.02 ; \mathrm{p}<.05)$.

The Wilcoxon test gave significant results at the 0.05 significance level on the scales Drug effects, High and Rush for the Stimulant Condition when comparing Phase 1 (stimulation) with Phase 2 (relaxation). The results are found in Table 4.

Table 4. Comparison of Phase 1 and 2 on the scales Drug effects, High and Rush for the Stimulant Condition. (Sig.= asymptotic significance).

\begin{tabular}{|l|c|c|}
\hline & Wilcoxon Z & Sig. \\
\hline Drug effect & -1.84 & .066 \\
\hline High & -2.32 & .042 \\
\hline Rush & -2.06 & .039 \\
\hline
\end{tabular}

When we compared the scores of all the scales between reproducing the effects of both the Stimulant and Alcohol Conditions, and for both the baseline and phase 1 using the Kolmogorov-Smirnov test for independent samples, we found no differences in the baseline, whereas reproducing the stimulant significantly increased the scores for Energy and Tension in the comparison made with reproducing alcohol effects. The results are found in Table 5.

Table 5. Comparison of the scores obtained with the scales for the Stimulant and Alcohol Conditions, for both the baseline and first phase. (Sig.= asymptotic significance).

\begin{tabular}{|l|l|c|c|}
\hline & & $\mathrm{Z}$ & Sig. \\
\hline BASELINE & Energy & .632 & .819 \\
\cline { 2 - 4 } & Tension & .316 & 1 \\
\cline { 2 - 4 } & GFP-FAS & .632 & .819 \\
\hline \multirow{4}{*}{$\begin{array}{l}\text { REPRODUCING } \\
\text { THE EUPHORIC } \\
\text { EFFECT }\end{array}$} & $\begin{array}{l}\text { Drug } \\
\text { effect }\end{array}$ & .949 & .329 \\
\cline { 2 - 4 } & High & .632 & .819 \\
\cline { 2 - 4 } & Rush & .949 & .329 \\
\cline { 2 - 4 } & Energy & 1.581 & .013 \\
\cline { 2 - 4 } & Tension & .632 & .819 \\
\cline { 2 - 4 } & GFP-FAS & 1.581 & .013 \\
\hline
\end{tabular}

We now show the graphs to illustrate the variation in the scores of the different scales for all the conditions.

In Figure 2 we can see the scores on scales Drug effects,
High and Rush for the Stimulant (two phases) and Alcohol Conditions.

We observe how the higher scores correspond to phase 1 of the Stimulant Condition (euphoric effects) and the lowest ones correspond to phase 2 of the same condition (relaxing effects).

Figure 3 offers the scores of scales Energy, Tension and GFP-FAS for both the Stimulant and Alcohol Conditions and for all the phases.

For the Stimulant Condition we can see that the euphoric effects considerably increase Energy and GFP$F A S$, while the relaxing effects lower them to the baseline, and also reduce Tension.

Whereas Tension remains at baseline levels with the Alcohol Condition, reproducing alcohol effects reduces Energy and GFP-FAS and goes below the baseline.

We can see that most of the curves in the two figures are inverted U-shaped. This may represent the characteristic curve of addiction, with scores increasing at the beginning (sensitization) and then progressively lowering during the next sessions (tolerance).

It is worth stressing some U-shaped curves, especially those for the Tension variable in the Alcohol Condition, and also for the Energy variable in the reproduction phase, which might indicate some adaptation to the depressor alcohol effect when reproduction sessions are repeated.

\section{Discussion}

This article presents the results of a single-case experiment on reproducing drug effects during 10 sessions (five reproduction sessions for each drug) on 5 consecutive days. The participant used the SRT alternatively and randomly to reproduce the effects of a psychostimulant (methylphenidate) and alcohol.

The statistical results reveal that the participant was capable of discriminating the effects of both drugs, and was able to clearly distinguish when their effects were reproduced with the SRT. This article also demonstrates that Drug Effect, High and Rush clearly increased when the participant was experiencing the maximum (euphoric) effects of both drugs compared to the baseline. It was also possible to distinguish two phases in the stimulant effects: a peak for euphoria, followed by a calm and relaxing phase.

Where the results of this experiment are clearly illustrated is in the two graphs, where we can see how 
Drug Effect, High and Rush tend to form an inverted U over the 5 days that the experiment lasts, particularly for the first two scales and for phase 1 (peak of euphoria) for the Stimulant Condition.

Energy and GFP-FAS also tend to form an inverted $U$, especially in the two Stimulant Condition phases. For the Alcohol Condition, GFP-FAS forms an inverted U, while Energy forms a U.

An inverted $U$ can be interpreted as proof of the addictive process, with an enhanced effect during the first sessions (sensitization) and a lessened effect during the following sessions (tolerance). For the Alcohol Condition, the Energy $U$ can be interpreted as a process of tolerance to the depressor effects of alcohol. In another experiment, where the subject reproduced the effects of another psychostimulant, ephedrine, over 5 consecutive days, a sensitization effect was also observed, but there was no tolerance effect [18].

The participant's subjective feelings about the potential addictive process were learnt during the next interview held with him. He revealed that during the week, he felt he wanted to experience the effects that he had managed to reproduce, but only to reproduce the psychostimulant effects. He felt a strong dislike to the Alcohol Condition as he was unable to reproduce the effect of feeling slightly drunk, but managed to reproduce the feeling very drunk effect. This aversive feeling (feeling sick, dizzy and generally unwell) made him reject this experience. Conversely, he found that reproducing the effects of methylphenidate was gratifying, especially in phase 2 (relaxation). He felt he wished to once again experience the feelings reproduced by the stimulant, but never felt the need to use the drug.

What all this allows us to understand is that it is possible to reproduce an addictive process of a drug with the $S R T$ without using the drug and that this type of addiction does not lead subjects to seek the real drug. This, in turn, allows us to deduce that the SRT procedure can be used to treat drug addictions, especially after verifying this by the $S R T$, as heroin and cocaine addict patients who underwent rehabilitation were capable of reducing their drug craving during a test session [31,38]. Moreover, the SRT can be used to improve emotional disorders in psychology and psychiatry because by knowing the "addictive process" that the SRT produces. When employed during several sessions, it is possible to intervene in any process phase in order to favor therapy. This has already been performed to enhance the sensitization to reproduced drug effects and to avoid tolerance $[18,19]$.
The limitations of this study are obvious since it is a single-case experimental design that includes only a few sessions. In order to continue making progress with the many suggestions made in this article about the advantages of using the $S R T$, it is necessary to work with much larger groups in the experiments, with both number of subjects and number of sessions. It is also necessary to work with a clinical sample so that the obtained results can be applied to this population. It is important to point out that apart from increasing the number of sessions in future studies, it would be most interesting to apply another type of quantitative analysis to better reflect the significance of the evolution of the scores. Our research team has already published dynamic mathematical models of differential equations to simulate the acute effect of a stimulant dose [39] and the complete addictive process of cocaine [40]. These findings must be applied to future research designs that follow the guidelines presented herein.

Despite all these limitations, this study is the first step to demonstrate that it is possible to "acquire an addiction" without drugs, which is beneficial for clinical and general populations. Besides that considered herein, the approach of this article, along with its title, offers a new look at addictions, which may suggest exploring new research routes and intervening in the broad psychology, psychiatry and neurology fields.

\section{REFERENCES}

[1] West R and Brown J. "Theory of addiction” (2 $\left.{ }^{\text {nd }} E d.\right)$. UK, John Wiley \& Sons, Ltd. (2013).

[2] Robinson TE and Berridge K.C. “Addiction”. Annu. Rev. Psychol. 54 (2003): 25-53.

[3] Solomon RL and Corbit JD. “An opponent-process theory of motivation: 1. Temporal dynamics of affect”. Psychol Rev 81 (1974): 119-145.

[4] Koob GF and Le Moal M. "Drug abuse: hedonic homeostatic dysregulation”. Science 278 (1997): 52-58.

[5] Koob GF and Le Moal M. "Drug addiction, dysregulation of reward, and allostasis". Neuropsychopharmacology 24 (2001): 97-129.

[6] Robinson TE and Berridge KC. "The incentive sensitization theory of addiction: some current issues”. Philos Trans R Soc Lond B Biol Sci. 363 (2008): 3137-3146.

[7] Robinson TE and Berridge KC. "The neural basis of drug craving: an incentive-sensitization theory of 
addiction”. Brain Res Rev. 18 (1993): 247-291.

[8] Koob GF and Le Moal M. "Neurobiology of Addiction”. Academic Press: London. (2006)

[9] Volkow ND, Fowler JS and Wang GJ. The addicted human brain viewed in the light of imaging studies: brain circuits and treatment strategies”. Neuropharmacology 47(Suppl 1) (2004): 3-13.

[10] Stewart J and Eikelboom R. "Conditioned Drug Effects”. In L.L. Iversen, S.D. Iversen \& S.H. Snyder (Eds.), Handbook of Psychopharmacology. New York: Plenum Press. 1987.

[11] Siegel S. "Pavolvian conditioning and drug overdose: When tolerance fails". Addiction Research and Theory 9 (2001): 503-513.

[12] CP O’Brien, et al. "Classical conditioning in human opioid dependence”. In S.R. Goldberg \& I.P. Stolerman (Eds.), Behavioral analysis of drug dependence. New York: Academic Press. (1986).

[13] CP O'Brien, et al. "Classical conditioning in drugdependent humans". Annals of the New York Academy of Sciences 654 (1992): 400-415.

[14] Amigó S. "Self-regulation Therapy: Suggestion Without Hypnosis”. In I. Kirsch, A. Capafons, E. Cardeña\& S. Amigó (Eds). Clinical Hypnosis and SelfRegulation Therapy: A cognitive-behavioral perspective, American Psychological Association, Washington. (1998).

[15] Amigó S. Manual of controlled drug use. Madrid, Spain: Liber Factory. (2014).

[16] Spanos NP and Chaves JF. Hypnosis: The CognitiveBehavioral Perspective. Buffalo, N.Y.: Prometeus Press. (1989).

[17] Amigó S. Sugar pills to experience cocaine and other drug effects: the Self-Regulation Therapy as a placebo without deception. EC Neurology 3.1 (2016): 320-331.

[18] Amigó S. "Self-regulation therapy and the voluntary reproduction of stimulant effects of ephedrine: possible therapeutic applications". Contemporary Hypnosis 11 (1994): 108-120.

[19] Amigó S. "Uso potencial del metilfenidato y la sugestión en el tratamiento psicológico y en el aumento de las potencialidades humanas: un estudio de caso”. Análisis y Modificación de Conducta 23 (1997): 863-890.
[20] GA Barr, et al. "Clasical conditioning decay and extintion of cocaine-induced hiperactivity and stereotypy”. Life Science 33(1983): 1341- 1351.

[21] RM Post, et al. "Drug-enviroment interaction: context dependency of cocaine induced behavioral sensitization”. Life Science 28 (1981): 755-760.

[22] Foltin RW and Haney M. "Conditioned effects of environmental stimuli paired with smoked cocaine in humans”. Psychopharmacology 149 (2000): 24-33.

[23] Beirness, D and Vogel-Sprott, M. "Alcohol tolerance in social drinkers: Operant and classical conditioning effects”. Psychopharmacology 84 (1984): 393.

[24] Drobes DJ, et al. "Classical conditioning mechanisms in alcohol dependence”. In Heather, Nick (Ed); Peters, Timothy J. (Ed); Stockwell, Tim (Ed). (2001), International handbook of alcohol dependence and problems (pp. 281-297). New York, NY, US: John Wiley \& Sons Ltd.

[25] Field M and Duka T. "Cues paired with a low dose of alcohol acquire conditioned incentive properties in social drinkers”. Psychopharmacology (Berl). 159(3) (2002): 325-34.

[26] Glautier S, Drummond C and Remington B. "Alcohol as an unconditioned stimulus in human classical conditioning”. Psychopharmacology (Berl) 116(3) (1994): 360-8.

[27] Little $\mathrm{HJ}$, et al. "Alcohol withdrawal and conditioning”. Alcohol Clin Exp Res 29(3) (2005): 45364.

[28] Sherman JE, Jorneby DE and Baker TB. "Classical conditioning with alcohol: Acquired preferences and aversions, tolerance, and urges/cravings”. In: Chaudron CD, Wilkinson DA, editors. Theories on alcoholism. Toronto: Addiction Research Foundation; pp. 173-287. (1988).

[29] Amigó S. La teoría del rasgo único de personalidad: hacia una teoría unificada del cerebro y la conducta. Valencia: Universidad Politécnica de Valencia. (2005).

[30] Amigó S and Ferrández C. "Experiencing Effects of Cocaine and Speed with Self-Regulation Therapy”. The Spanish Journal of Psychology 18 (2015): 1-10.

[31] S Amigó, et al. "Colocarse sin droga. Un nuevo enfoque desde la reducción del daño para dependientes a la cocaína”. Informació Psicològica 89 (2007): 75-87.

[32] Amigó S, Caselles A and Micó J. C. "Self-regulation 
therapy to reproduce drug effects: A suggestion technique to change personality and DRD3 gene expression". The International Journal of Clinical and Experimental Hypnosis 61 (2013): 282-304.

[33] Amigó S, Caselles A, Micó JC and García J.M. "Dynamics of the unique trait of personality: blood's glutamate in response to methylphenidate and conditioning”. Revista Internacional de Sistemas, 16 (2009): 35-40.

[34] Micó JC, Amigó S and Caselles A. "Changing the General Factor of Personality and the c-fos expression with methylphenidate and Self-Regulation Therapy". The Spanish Journal of Psychology, 15(2) (2012): 850-867.

[35] Amigó S, Micó JC and Caselles A. "Five adjectives to explain the whole personality: a brief scale of personality”. Revista Internacional de Sistemas, 16 (2009): 41-43.

[36] Thayer, RE. "Problem perception, optimism, and related states as a function of time of day (diurnal rhythm) and moderate exercise. Two arousal systems in interaction”. Motivation and Emotion 11 (1987): 19-36.

[37] Kazdin AE. "Statistical analysis for single case experimental designs”. In DH Barlow \& M Hersen (Eds.), Single Case Experimental Designs. pp. 155-285. New York: Pergamon Press. (1984).

[38] Amigó S and Infanzón M.E. "Heroína sin heroína: la sugestión como sustituto de las drogas”. Análisis y Modificación de Conducta, 25 (1999): 751-781.

[39] Caselles A, Micó, C, and Amigó S. "Dynamics of the General Factor of Personality in response to single dose of caffeine”. The Spanish Journal of Psychology, 14 (2011): 675-692.

[40] Caselles A, Micó J C and Amigó S. "Cocaine addiction and personality: A mathematical model”. British Journal of Mathematical and Statistical Psychology, 63 (2010): 449-480. 


\section{Appendix}

Table 1. Means $(\overline{\mathrm{X}})$ and standard deviations (SD) of the scores obtained with the different scales for the three phases in this study.

\begin{tabular}{|c|c|c|c|c|c|}
\hline \multirow{2}{*}{ PHASE } & SCALES & \multicolumn{2}{|c|}{ STIMULANT } & \multicolumn{2}{c|}{ ALCOHOL } \\
\cline { 3 - 6 } & & $\overline{\mathrm{X}}$ & $\mathrm{SD}$ & $\overline{\mathrm{X}}$ & $\mathrm{SD}$ \\
\hline \multirow{4}{*}{ BASELINE } & Drug effect & - & - & - & - \\
\cline { 2 - 6 } & High & - & - & - & - \\
\cline { 2 - 6 } & Rush & - & - & - & \\
\cline { 2 - 6 } & Energy & 10.60 & 2.07 & 14.60 & 4.98 \\
\cline { 2 - 6 } & Tension & 30.60 & 3.28 & 29.40 & 4.50 \\
\cline { 2 - 6 } & GFP-FAS & 3.60 & 4.15 & 17 & 4.74 \\
\hline \multirow{4}{*}{$\begin{array}{c}\text { EUPHORIC } \\
\text { EFFECTS }\end{array}$} & Drug effect & 7 & 1.73 & 5.40 & 1.81 \\
\cline { 2 - 6 } & High & 7.40 & 1.81 & 6.40 & 1.51 \\
\cline { 2 - 6 } & Rush & 9 & 1.73 & 7.20 & 1.64 \\
\cline { 2 - 6 } & Energy & 34.20 & 2.58 & 7.60 & 2.19 \\
\cline { 2 - 6 } & Tension & 29.80 & 5.97 & 28.40 & 4.72 \\
\cline { 2 - 6 } & GFP-FAS & 36.20 & 5.89 & 11.80 & 2.58 \\
\hline \multirow{3}{*}{$\begin{array}{c}\text { REPRODUCING } \\
\text { RELAXING }\end{array}$} & Drug effect & 4.40 & .54 & & \\
\cline { 2 - 6 } & High & 4.20 & 2.09 & & \\
\cline { 2 - 6 } & Rush & 0 & 0 & & \\
\cline { 2 - 6 } & Energy & 13 & 4.84 & & \\
\cline { 2 - 6 } & Tension & 15.20 & 5.16 & & \\
\cline { 2 - 6 } & GFP-FAS & 18 & 6.40 & & \\
\hline
\end{tabular}

Table 3. Pair-wise comparisons made of the different scales that measured the effect of reproducing stimulants in the three phases (information on positive and negative ranges has been left out).

\begin{tabular}{|c|c|c|c|c|c|c|c|}
\hline \multirow{2}{*}{ STIMULANT } & \multirow{2}{*}{ SCALES } & \multicolumn{2}{|c|}{ Phase1-LB } & \multicolumn{2}{c|}{ Phase2-LB } & \multicolumn{2}{c|}{ Phase2-Phase1 } \\
\cline { 3 - 8 } & & $\mathrm{Z}$ & $\mathrm{Sig}$ & $\mathrm{Z}$ & $\mathrm{Sig}$ & $\mathrm{Z}$ & Sig \\
\hline & Energy & -2.03 & .042 & -1.46 & .14 & -2.03 & .042 \\
\cline { 2 - 8 } & Tension & -.54 & .58 & -2.04 & .041 & -2.02 & .043 \\
\cline { 2 - 8 } & GFP-FAS & -2.02 & .043 & -1.76 & .078 & -2.03 & .042 \\
\hline \multirow{2}{*}{ ALCOHOL } & Energy & -2.02 & .043 & & & & \\
\cline { 2 - 8 } & Tension & -.55 & .58 & & & & \\
\cline { 2 - 8 } & GFP-FAS & -1.82 & .068 & & & & \\
\hline
\end{tabular}

Figure 2. Scores of the scales Drug effects, High and Rush for the Stimulant (phases ST1-stimulant and ST2-relaxing) and Alcohol Conditions.

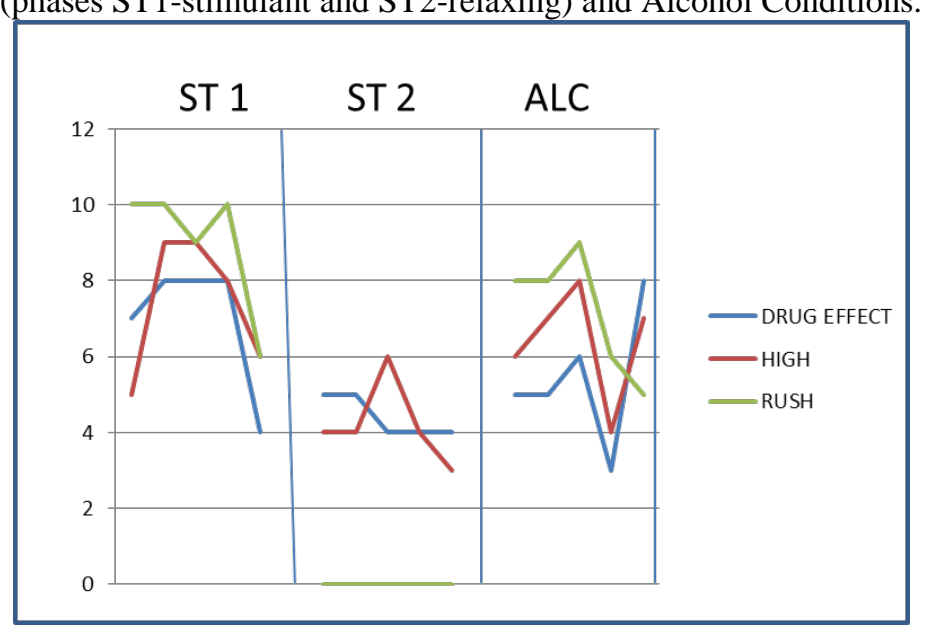


Figure 3. Scores on scales Energy, Tension and GFP-FAS for both the Stimulant and Alcohol Conditions and for all the phases.

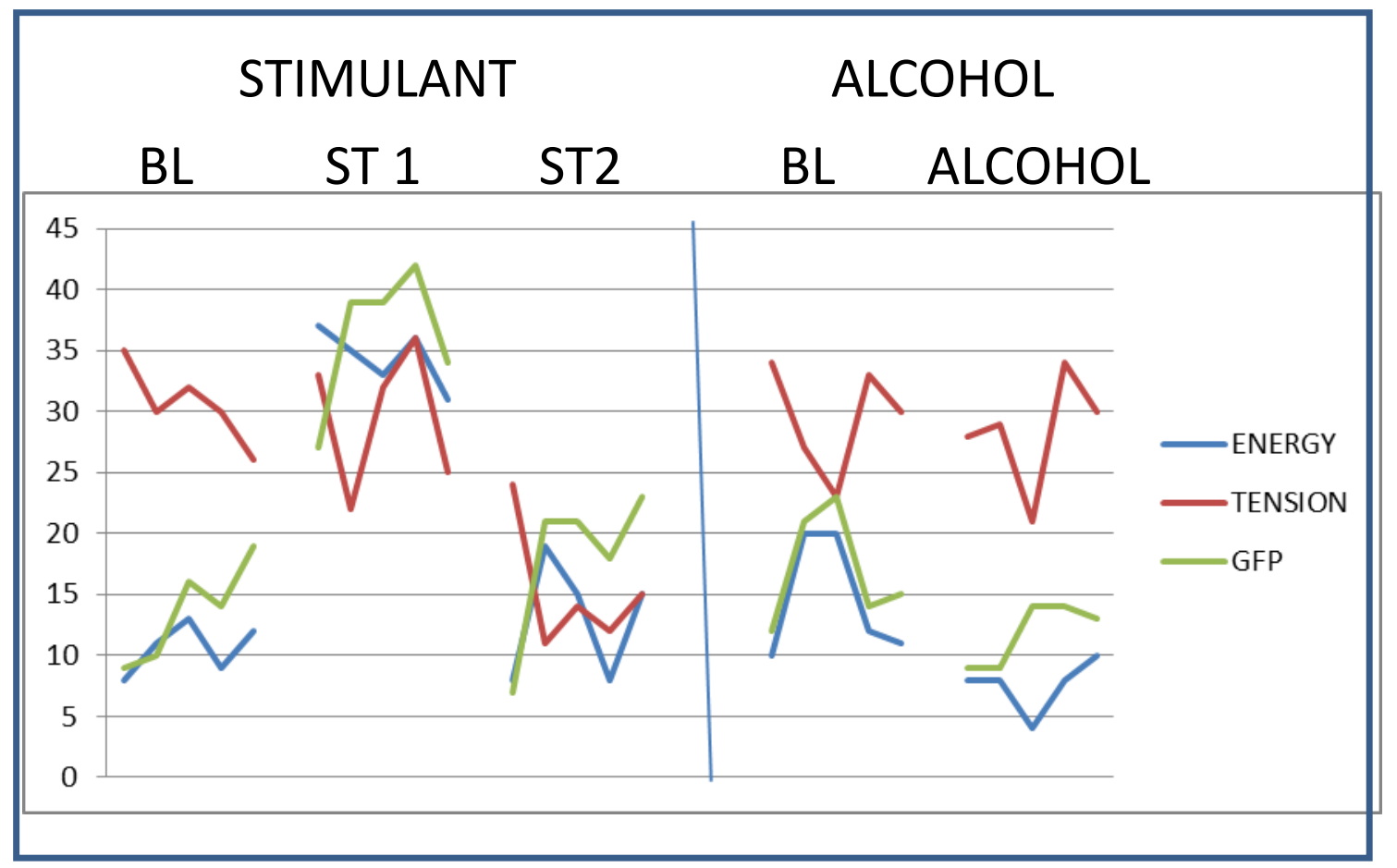

